\title{
Discrimination of area differences by the harbor seal'
}

STEPHEN H. FEINSTEIN AND CHARLES E. RICE STANFORD RESEARCH INSTITUTE, MENLO PARK, CALIFORNIA

An earlier investigation of the underwater size discrimination abilities of the California sea lion (Zalophus californianus) was replicated with Harbor seals (Phoca vitulina). Performance was equivalent even though there was a marked difference in test behavior and general activity level.

Previous work by Schusterman, Kellogg, \& Rice (1965) indicates that the California sea lion (Zalophus californianus) is capable of reasonably good size discrimination under water. This study is a replication of the size discrimination work with the Harbor seal (Phoca vitulina). It should be noted that while both species belong to the Order Pinnipedia, Phocabelongs to the Super-family Phocoidea and Zalophus to the Super-family Otarioidea, so that they are distinctly different animals anatomically.

\section{Subjects}

The Ss were one male (Runt) and one female (Goldie) Harbor seal (Phoca vitulina), approximately eight months old at the beginning of the experiment.

\section{Apparafus}

The experiment was conducted in a 13,000 gallon, fresh water, circular plastic tank modified (Fig. 1) to provide an alley $19 \mathrm{ft}$. long and $7 \mathrm{ft}$. wide. One end of the alley contained a ramp (A) to allow the animal to enter and leave the water. The other end of the alley

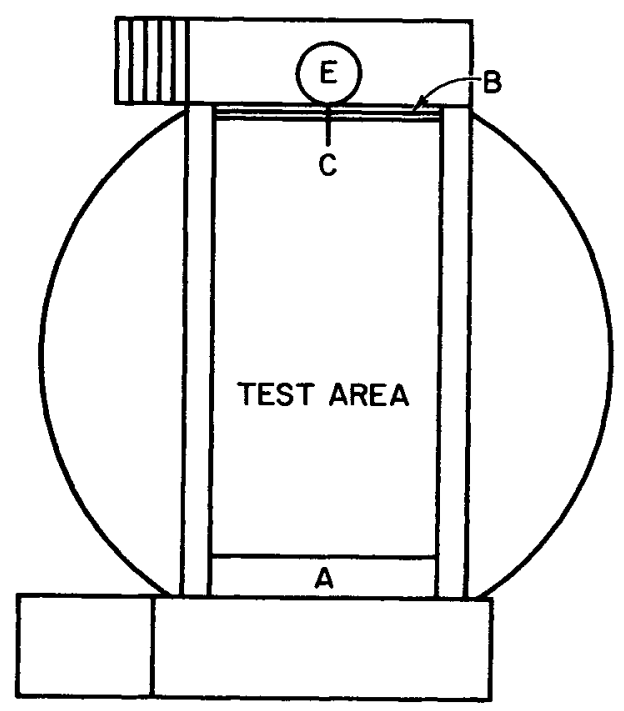

Fig. 1. Diagram of the test area (19 ft. $\times 7 \mathrm{ft} . \times 4 \mathrm{ft}$.), entrance ramp (A), visual stimulus presentation apparatus $(B)$, choice point (C) 18 -in. in front of visual stimuli, and experimenter's (E) position behind a plywood screen. contained a frame and pulley system for presenting two visual stimuli simultaneously (B). The stimuli, flat discs of .050 aluminum painted flat black, were separated by an 18-in. plywood divider (C) which allowed the Ss to visually inspect both targets up to a minimum of $18 \mathrm{in}$. (choice point). Both the divider and the field behind the stimuli were painted flat white. The experimenter (E) sat behind a plywood screen (D) which shielded the presentation apparatus from the $S$ until the targets were lowered into the water. The stimuli centers were $2 \mathrm{ft}$. below the surface of the water when in the presentation position. Water in the tank was continuously filtered through a diatomacious earth filter which was recharged daily in order to maintain clarity.

\section{Procedure}

The seals were given preliminary training on land with a hand-held black square target until a pressing response was established and then were taken into the testing tank where further training established the following test behavior sequence: (1) the animal stationed itself at the entrance ramp (A) with its head out of water; (2) when $E$ presented the stimuli, the noise from the frame and pulley system signaled the animal to swim underwater toward the stimuli; (3) S chose the right or left stimulus disc from a minimum distance of $18 \mathrm{in}$. and pressed the selected stimulus with his snout. The position of the stimulus was an irrelevant cue throughout this experiment. The stimulus display was withdrawn immediately following $S$ 's indicator response, and correct responses were reinforced with a small piece of cut herring (Clupea pallasi) which came from the animals's daily ration. The remainder of the ration was given to the animal immediately after it left the testing tank.

In order to determine whether a size preference already existed for the Ss, two discs differing in area by a ratio of 6.72:1 were presented simultaneously for 20 trials. The position of the stimuli was randomly alternated from right to left and responses to either target were reinforced. Runt showed a preference for the larger $(p<.05)$ and Goldie for the smaller $(p<.001)$ stimulus. An additional 50 training trials were run which called for reinforcement only when the preferred target was pressed. This served to firmly establish an animal's response to the appropriate stimulus size relationship.

The preliminary training sessions were designed to establish a starting point in the original series of size comparisons which had been used with the California sea lion (Schusterman et al, 1965). That point was 
selected on the basis of the smallest area ratio which could be correctly responded to on 95 out of 100 trials. In order to maximize performance, training sessions were run with each of the stimulus pairs to allow experience with this kind of visual discrimination problem. The Ss were tested with discs that had area ratios of $2.59: 1,1.61: 1,1.27: 1,1.13: 1,1.06: 1$, and 1.03:1. The first three of these ratios were tested singly until the animals reached criterion. Beginning with the third ratio, 1.27:1, a test session included one easy and one or more difficult discriminations, in

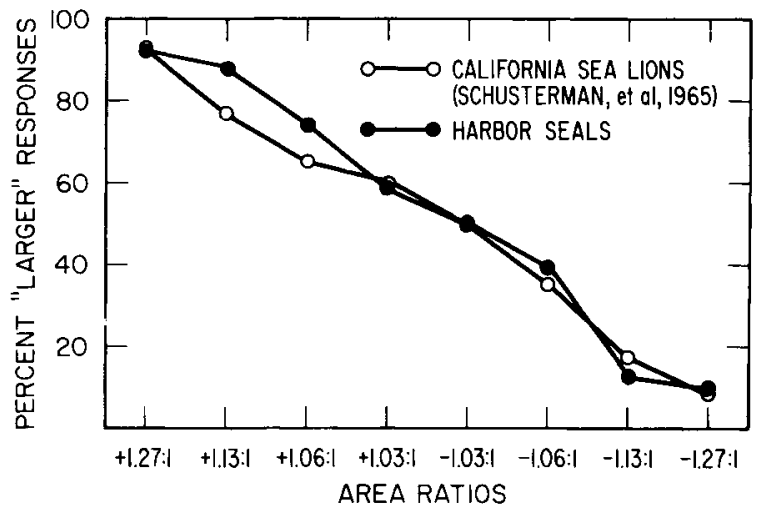

Fig. 2. A comparison of the ability of Harbor seals (Phoca vitulina) and Califomia sea lions (Zalophus californianus) to discriminate small differences in the area of flat black discs. Percent "larger" responses refers to discrimination of the relative size of the variable stimulus. order to reduce the level of frustration resulting from non-reinforced trials.

The threshold data are based on all trials run after a starting point was determined. This amounted to 50 trials per day for 20 days.

\section{Results and Discussion}

Figure 2 presents a comparison between the mean Harbor seal performance and that of the California sea lion as obtained by Schusterman et al (1965). Inspection of the curves indicates that despite the diverse structural and behavioral adaptations of these two pinniped forms, the ability to perceive and respond correctly to small differences in surface area is equivalent.

The Harbor seal is a wary animal that generally avoids contact with humans or other animals. We found that though they were quick to learn the test procedure, they sometimes performed erratically. Generally, they were slow and deliberate in approaching the stimuli, and would often ignore the food reward while continuing to follow the test procedure. Food deprivation was not effective in reducing the frequency of non-test-oriented behavior.

\section{Reference}

Schusterman, R. J., Kellogg, W. N., \& Rice, C. E. Underwater visual discrimination by the California sea lion. Science, 1965 , 147, 1594-1596.

\section{Note}

1. This research was supported by NSF grant GB-1437. The authors are indebted to Dr. R. J. Schusterman for his encouragement and advice. 